Supplement of The Cryosphere, 12, 3383-3407, 2018

https://doi.org/10.5194/tc-12-3383-2018-supplement

(C) Author(s) 2018. This work is distributed under

the Creative Commons Attribution 4.0 License.

(c) (1)

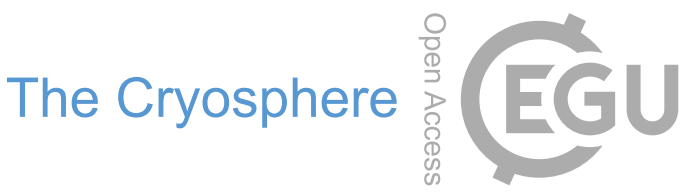

Supplement of

\title{
Basal control of supraglacial meltwater catchments on the Greenland Ice Sheet
}

Josh Crozier et al.

Correspondence to: Josh Crozier (crozierjosh1@gmail.com)

The copyright of individual parts of the supplement might differ from the CC BY 4.0 License. 


\section{S1 Transfer Function Dependence on 2D Bed Topography}

The two-dimensionality of the transfer functions is important, as mentioned in section 2.3.2 of the main text. This can be demonstrated by examining a scenario with different single-wavenumber components of bed topography (plane-waves) that have the same apparent wavenumbers in a transect interpolated across bed topography along an ice flowline (a bed elevation profile along the ice flow direction). The same apparent wavenumber in the ice flow direction $k_{U}$ could arise from any single wavenumber component of bed topography with absolute wavenumber $k=k_{U} \cos (\theta)$ aligned at angle $\theta$ from the ice flow direction, where the plane-wave ridge alignment is perpendicular to the direction of ice flow when $\theta=0$. If we evaluate the predicted transfer functions for a given $k_{U}$ and set $k=k_{U} \cos (\theta)$ for a range of $\theta$, transfer amplitude and phase will both depend upon $\theta$ even though the apparent flowline bed topography is the same for all $\theta \neq \frac{n \pi}{2}$. We use the bed topography transfer functions from Gudmundsson (2003) to calculate

$$
\begin{aligned}
\hat{A}_{B}(\theta)= & \left(k_{U}^{*(2)} \cos (\theta)\left(\cosh \left(k_{U}^{*} \cos (\theta)\right)\left(C^{0 *(2)} k_{U}^{*(2)} \cos ^{2}(\theta)+2 U^{*}\right)+C^{0 *} k_{U}^{*} U^{*} \cos (\theta) \sinh \left(k_{U}^{*} \cos (\theta)\right)\right)\right) / \ldots \\
& \left(k_{U}^{*(4)} U^{*(2)} \cos ^{2}(\theta)\left(\frac{1}{2} C^{0 *} k_{U}^{*} \cos (\theta) \sinh \left(2 k_{U}^{*} \cos (\theta)\right)+k_{U}^{*(2)} U^{*} \cos ^{2}(\theta)+\cosh ^{2}\left(k_{U}^{*} \cos (\theta)\right)+1\right)^{2}+\ldots\right. \\
& \left.\cot ^{2}(\alpha)\left(k_{U}^{*} \cos (\theta)\left(C^{0 *} \sinh ^{2}\left(k_{U}^{*} \cos (\theta)\right)-1\right)+\frac{1}{2} \sinh \left(2 k_{U}^{*} \cos (\theta)\right)\right)^{2}\right)^{1 / 2}
\end{aligned}
$$

It can similarly be shown that bed topography transfer phase also depends upon $\theta$ as

$\hat{\phi}_{B}(\theta)=-\operatorname{arccot}\left(\frac{k_{U}^{*(2)} v \tan (\alpha) \cos (\theta)\left(C^{0 *} k_{U}^{*} \cos (\theta) \sinh \left(2 k_{U}^{*} \cos (\theta)\right)+2 k_{U}^{*(2)} v \cos ^{2}(\theta)+\cosh \left(2 k_{U}^{*} \cos (\theta)\right)+3\right)}{2 k_{U}^{*} \cos (\theta)\left(C^{0 *} \sinh ^{2}\left(k_{U}^{*} \cos (\theta)\right)-1\right)+\sinh \left(2 k_{U}^{*} \cos (\theta)\right)}\right)$.

These equations give the potential variation in bed topography transfer amplitude and phase that could result from examining

bed topography only along ice flowline transects, and thus demonstrate the importance of predicting the ice surface over 2D bed topography, since the configuration of bed topography off of a flowline can influence the ice surface over said flowline. With ice flow parameters representative of the western Greenland Ice Sheet ablation zone, the predicted transfer amplitude of IDC-scale $(\sim 1-10 \mathrm{~km})$ bed features could vary by up to a factor of 10 depending upon the 2D alignment of those features (Fig. $\mathrm{S} 1)$. 


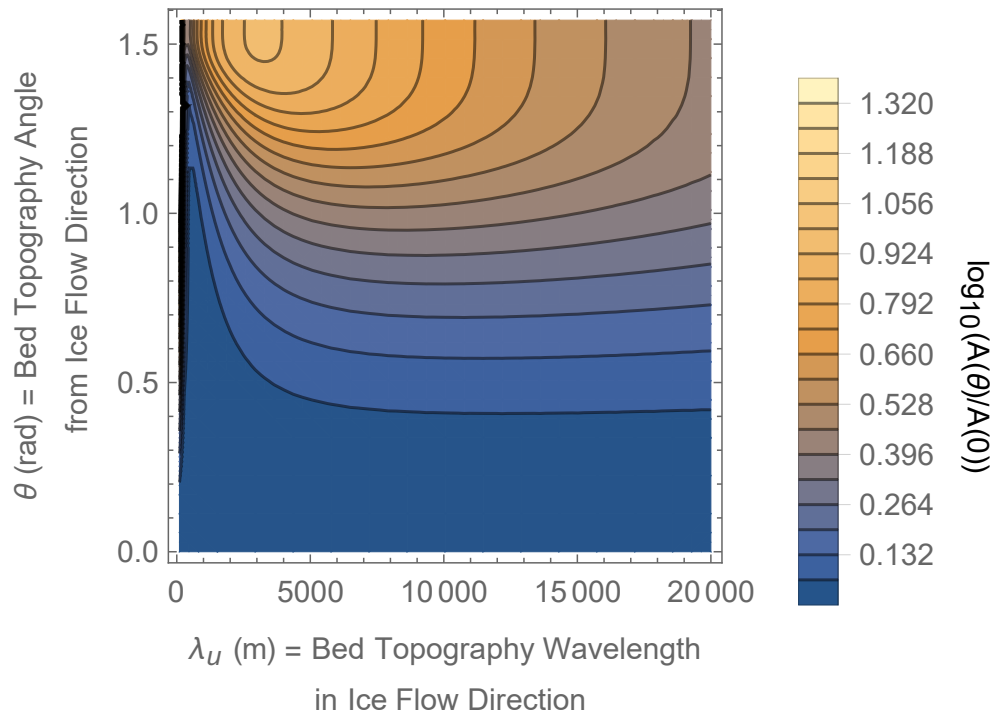

Figure S1. Effect of 2D bed topography on ice flowline bed topography transfer amplitude, defined in Appendix S1. $A(\theta)$ is predicted transfer amplitude for ice-flowline-equivalent bed topography aligned at angle $\theta$ from the ice flow direction, and $A(0)$ is the predicted flowline-only (equivalent to $\theta=0$ ) transfer amplitude. Ice flow parameters used are from region R1 (Fig. 1.A and Table 1 of the main text) with $\eta=10^{14} \mathrm{~Pa}$ s and $C^{0 *}=10$. 


\section{S2 Conformity Metrics}

We use two conformity metrics, $\% d$ and $\Lambda$, to examine how well stream network geometry is explained by surface topography lowpass filtered at various wavelengths as described in section 2.4.3 of the main text. We project stream networks onto filtered surfaces and then for each stream we calculate conformity factor as:

$5 \quad \Lambda=\frac{1}{L} \int_{l=1}^{L}\left|\frac{\boldsymbol{D}(l) \bullet(\boldsymbol{\nabla} Z(l))}{\|\boldsymbol{D}(l)\|\|\boldsymbol{\nabla} Z(l)\|}\right| d l$

where \|\| indicates vector magnitude, $\boldsymbol{D}(l)=\left(D_{x}(l), D_{y}(l)\right)$ is the stream channel horizontal direction vector (the east-north direction of water flow, calculated with a 2 nd order centered difference approximation of the stream channel tangent in mapview) at location $l$ along a stream of length $L$, and $\nabla Z(l)$ is the corresponding ice surface gradient $\left(\left.\frac{\partial Z}{\partial x}\right|_{l},\left.\frac{\partial Z}{\partial y}\right|_{l}\right)$ (calculated with a 2 nd order centered difference approximation). We calculate percent downhill (here using discrete notation) as:

$10 \% d=\frac{100}{N-1} \sum_{n=1}^{N-1} \begin{cases}0 & \text { if } Z(n) \leq Z(n+1) \\ 1 & \text { if } Z(n)>Z(n+1)\end{cases}$

where $n$ indexes discrete location along a stream ( $n$ increases in the downstream direction), $Z(n)$ is the corresponding ice surface elevation, and $N$ is the number of discrete locations along the stream, where each location corresponds to a DEM pixel. To calculate $\% d$ and $\Lambda$ for a whole stream network we calculate $\% d$ and $\Lambda$ for each stream segment in the network, then take a weighted average of each metric over all stream segments, where data from each stream segment is weighted by the number of data points in that segment $(N)$. 

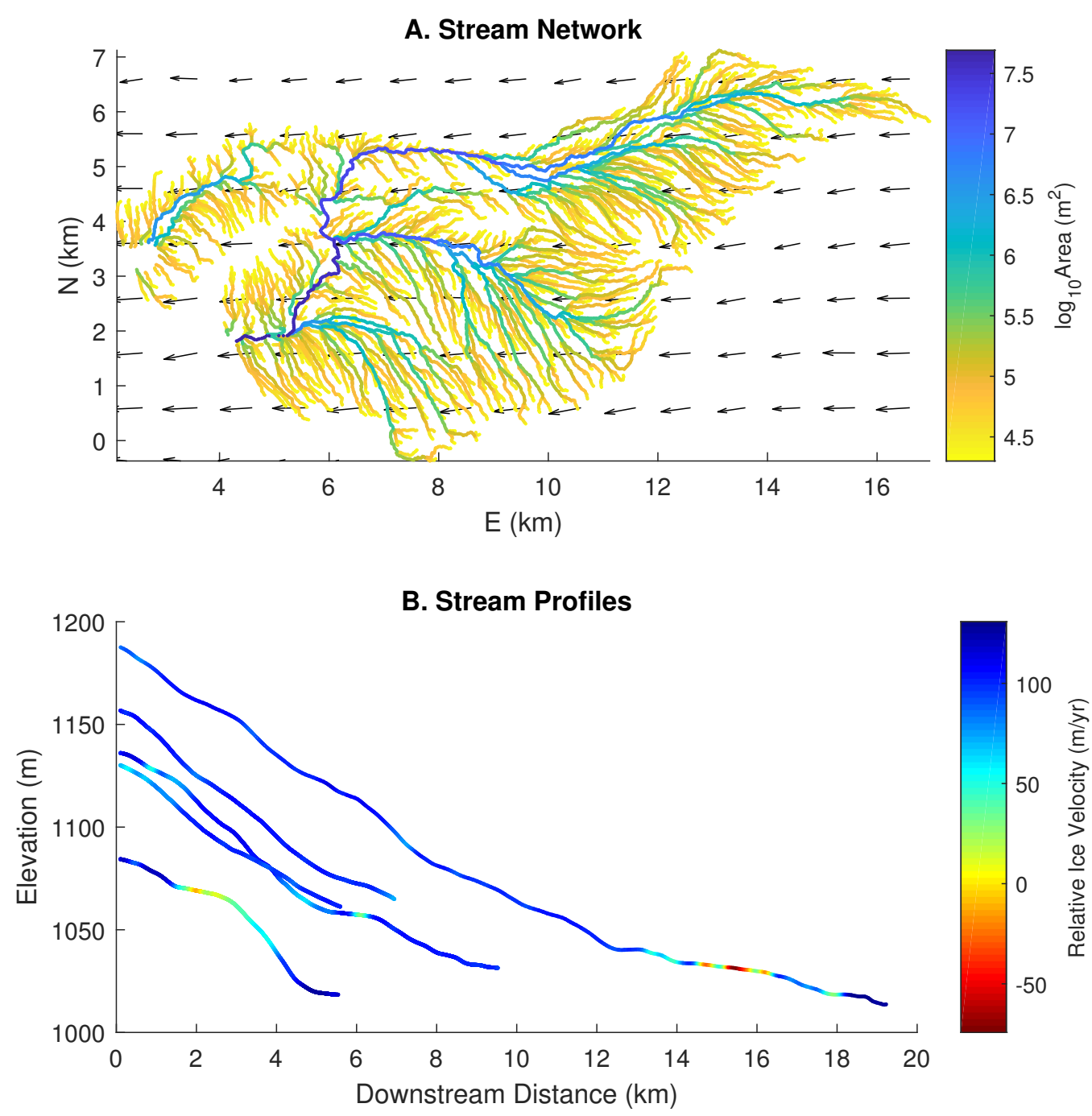

Figure S2. (A) Stream network obtained by flow routing from study region R1 (Fig. 1.A and Table 1 of the main text) colored by accumulated upstream drainage area; black arrows indicate ice surface velocity field. (B) Smoothed longitudinal stream elevation profiles from the longest streams in this network, colored by the component of ice surface velocity in the direction of stream flow (indicating stream meanders, negative values are where the stream is flowing against the ice flow direction). Fluvial incision-dominated profiles with a fixed terminal elevation should generally approach concave-up longitudinal profiles (Karlstrom and Yang, 2016). There are many visible convexities in supraglacial stream profiles, many of which do not simply correspond with stream meanders. 

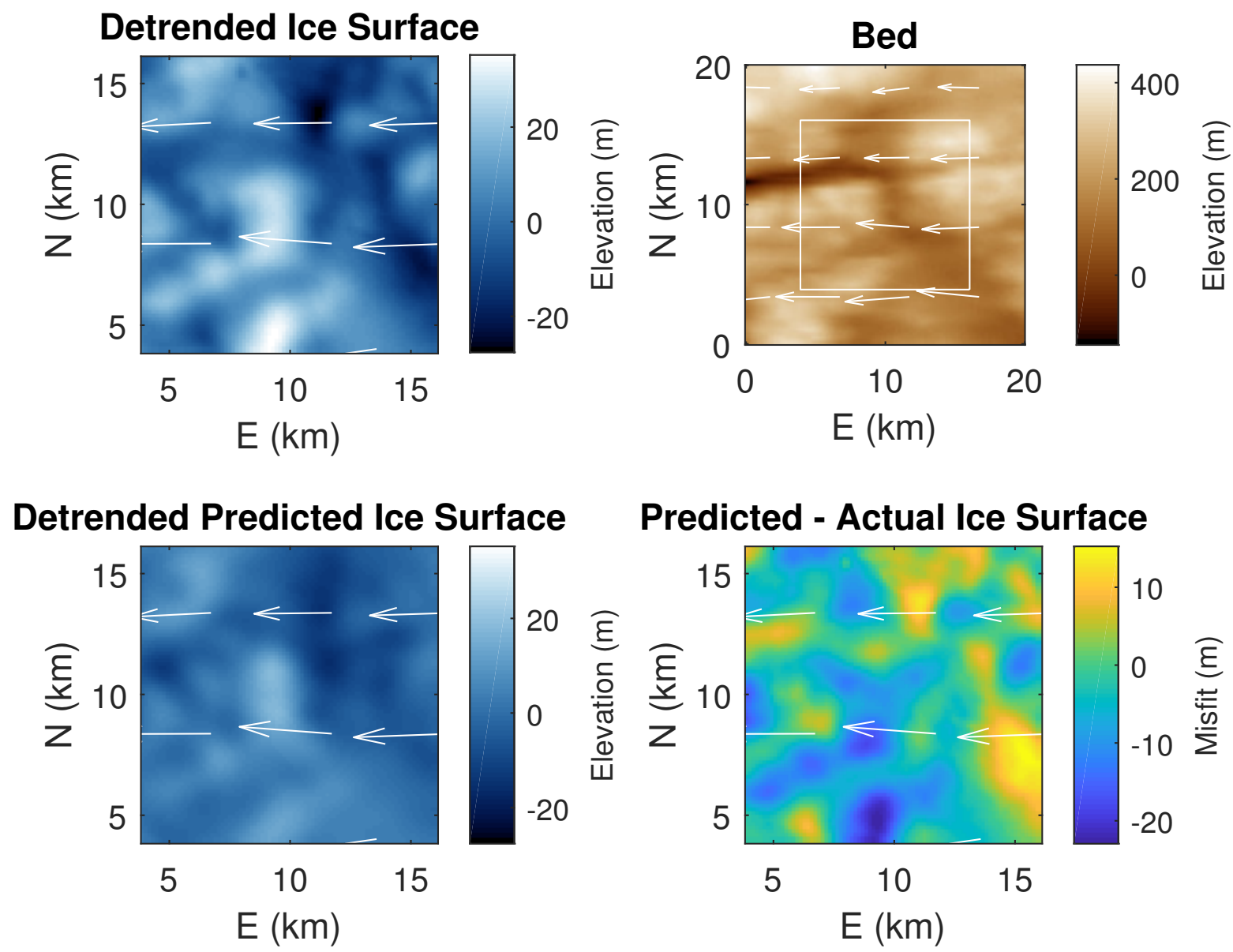

Figure S3. (top left) Detrended ice surface DEM from study region R2 (Fig. 1.A and Table 1 in main text). (bottom left) Detrended bed topography transfer predicted ice surface, with $\eta=10^{14} \mathrm{~Pa}$ s and $C^{0 *}=10$. (top right) Underlying BedMachine bed DEM, white box indicates the area over which the ice surface is predicted. (bottom right) Prediction misfit (subtraction between the actual and predicted ice surfaces). White arrows in all plots indicate ice surface velocity field. 


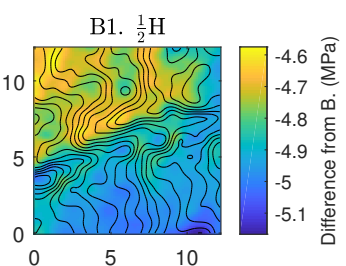

B3. $\frac{1}{2} \mathrm{U}$

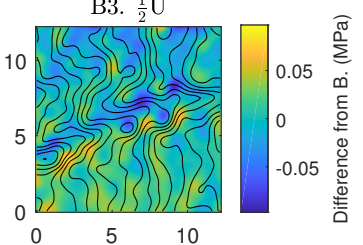

B5. $\frac{1}{2} \mathrm{C}^{0 *}$

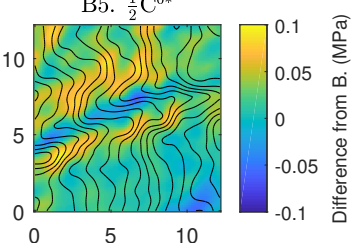

B7. $\frac{1}{2} \alpha$

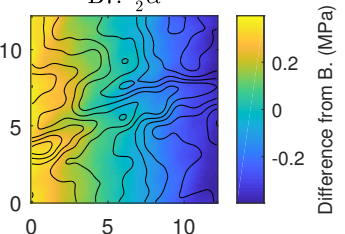

A. Subglacial Hydraulic

Potential under

Actual Surface DEM

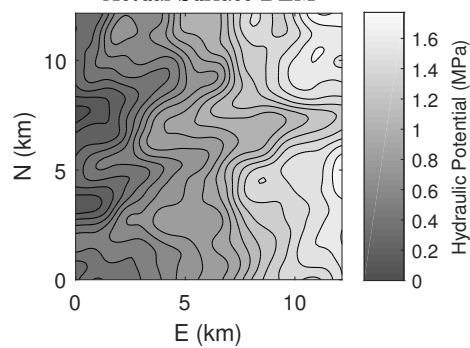

B. Subglacial Hydraulic Potential under Predicted Surface

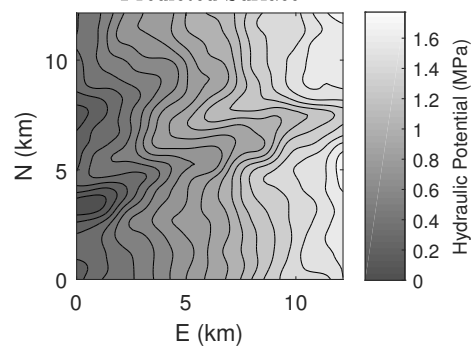

B2. $2 \mathrm{H}$

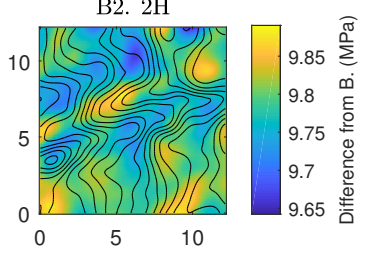

B4. $2 \mathrm{U}$

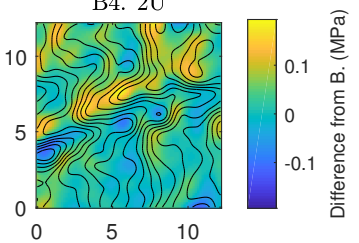

B6. $2 \mathrm{C}^{0 *}$

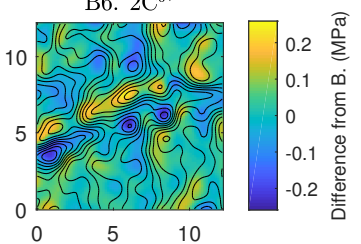

B8. $2 \alpha$

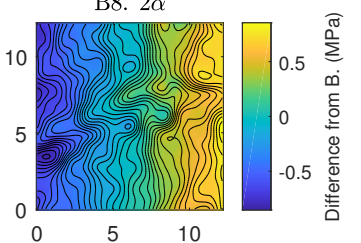

Figure S4. (A) Subglacial hydraulic potential calculated under the actual ice surface DEM from BedMachine/GIMP, (Howat et al., 2014; Morlighem et al., 2017). Black contours in all plots are 0.1 MPa hydraulic potential contours. (B, B1-B8) Subglacial hydraulic potential calculated under the bed topography transfer predicted ice surface with various ice flow parameters. Plots B1-B8 are colored by difference from the baseline hydraulic potential in plot B. From study region R1 (Fig. 1.A and Table 1 in the main text) with $\eta=10^{14} \mathrm{~Pa} s$ and baseline $C^{0 *}=10$. Changes to all ice flow parameters result in at least subtle changes in the hydraulic potential gradient (which drives water flow). 


\section{References}

Gudmundsson, G. H.: Transmission of basal variability to a glacier surface, Journal of Geophysical Research, 108, https://doi.org/10.1029/2002JB002107, 2003.

Howat, I. M., Negrete, A., and Smith, B. E.: The Greenland Ice Mapping Project (GIMP) land classification and surface elevation data sets, The Cryosphere, 8, 1509-1518, https://doi.org/10.5194/tc-8-1509-2014, 2014.

Karlstrom, L. and Yang, K.: Fluvial supraglacial landscape evolution on the Greenland Ice Sheet, Geophysical Research Letters, 43, 26832692, https://doi.org/10.1002/2016GL067697, 2016.

Morlighem, M., Williams, C. N., Rignot, E., An, L., Arndt, J. E., Bamber, J. L., Catania, G., Chauché, N., Dowdeswell, J. A., Dorschel, B., Fenty, I., Hogan, K., Howat, I., Hubbard, A., Jakobsson, M., Jordan, T. M., Kjeldsen, K. K., Millan, R., Mayer, L., Mouginot, J., Noël, B. P. Y., O’Cofaigh, C., Palmer, S., Rysgaard, S., Seroussi, H., Siegert, M. J., Slabon, P., Straneo, F., van den Broeke, M. R., Weinrebe, W., Wood, M., and Zinglersen, K. B.: BedMachine v3: Complete Bed Topography and Ocean Bathymetry Mapping of Greenland From Multibeam Echo Sounding Combined With Mass Conservation, Geophysical Research Letters, 44, 11,051-11,061, https://doi.org/10.1002/2017GL074954, 2017. 